\title{
Ovipositional preference and larval-early adult performance of two generalist lacewing predators of aphids in pecans
}

\author{
Mette Kjøbek Petersen*,1 and Martha S. Hunter \\ Department of Entomology, The University of Arizona, Forbes Building Room 410, Tucson, AZ 85721, USA
}

Received 8 March 2001; accepted 28 April 2002

\begin{abstract}
We examined the ovipositional preference and larval to early adult performance of two generalist, predatory green lacewing species Chrysoperla comanche (Banks) and Chrysopa nigricornis Burmeister. Both of these predators are abundant in pecan trees (Carya illinoensis (Wagenh) K. Kock) in southern Arizona where two specialist aphids Monellia caryella (Fitch) and Melanocallis caryaefoliae (Davis) are found. Ovipositional preference was tested in a three-way choice experiment with pecan seedlings infested with one of the two aphid species or without aphids. Females of both green lacewing species showed a significant preference for ovipositing on plants bearing aphids, but only C. comanche distinguished between the two aphid species. Both aphid species were suitable for larval development and developmental time was not affected by aphid treatment. C. nigricornis pupae were significantly heavier when larvae were fed only $M$. caryaefoliae, but no difference in pupal weight was found for $C$. comanche. The pre-oviposition period was significantly longer for $C$. nigricornis females that were fed a mixture of the two aphid species during larval development compared with each aphid species alone. However, aphid diet did not affect the number of eggs laid by either species during the first five days of oviposition. (c) 2002 Elsevier Science (USA). All rights reserved.
\end{abstract}

Keywords: Neuroptera; Chrysopidae; Chrysopa nigricornis; Chrysoperla comanche; Monellia caryella; Blackmargined pecan aphid; Melanocallis caryaefoliae; Black pecan aphid; Carya illinoensis

\section{Introduction}

Generalist predators frequently have complex behavioral mechanisms for finding, choosing, and consuming their prey (e.g., Hagen, 1987; Hagen et al., 1999; Scott and Barlow, 1990). In spite of a rich literature on predator ovipositional behavior and foraging (e.g., Albuquerque et al., 1997; Bargen et al., 1998; Hagen et al., 1999; Hodek and Honek, 1996; Richards and Evans, 1998; Sadeghi and Gilbert, 2000), relatively few experiments have evaluated the consequences of ovipositional site preferences of polyphagous predators with respect to the performance of offspring feeding on prey at those sites.

\footnotetext{
${ }^{*}$ Corresponding author. Fax: +46-1867-2890.

E-mail addresses: mette.petersen@evp.slu.se (M.K. Petersen), mhunter@ag.arizona.edu (M.S. Hunter).

${ }^{1}$ Address for correspondence: Department of Ecology and Crop Production Science, Swedish University of Agricultural Sciences, Box 7043, SE-750 07 Uppsala, Sweden.
}

The link between ovipositional preference of the mother and performance of the offspring has been most intensively studied in herbivores, where the correlation ranges from good to poor (e.g., Nylin and Janz, 1993; Thompson, 1988; Via, 1986; Yamaga and Ohgushi, 1999). One factor that is predicted to influence the fit is the degree of specialization of the herbivore (i.e., the "parasite/grazer hypothesis" of Thompson (1988)). When the offspring have generalized feeding habits and are mobile enough to move to another plant or there are different requirements for juvenile and adult feeding, ovipositing females may show little discrimination among host plants or may even lay eggs off of the plant (Thompson, 1988).

In most hymenopteran parasitoids, the reliance on maternal behavior is absolute; here, the consequence of ovipositing outside the range of suitable hosts is lethal and even relative generalists oviposit almost exclusively on hosts that are at least somewhat suitable for development. Among hosts of variable quality, parasitoids may preferentially oviposit in or on high quality hosts 
(Brodeur et al., 1998; Kraaijeveld et al., 1995) or accept all hosts equally when they are limited by low host encounter rates (Janssen, 1989).

One might expect the link between preference and performance to be weaker in generalist predators because offspring are not as dependent on the quality of individual prey for survival. However, the location of oviposition sites is clearly important to generalist predator fitness and many studies have shown that factors such as microhabitat, predation risk, prey type, prey density, and the age structure of a prey patch may all influence the oviposition behavior (Bargen et al., 1998; Doumbia et al., 1998; Kan, 1988; Lucas and Brodeur, 1999; Sadeghi and Gilbert, 2000).

It is also clear that different prey species may provide different food qualities to generalist predators, and some may be deterrent or even toxic, even to extreme generalists (Albuquerque et al., 1997; Bilde and Toft, 1994; Toft, 1995; Toft and Wise, 1999). Some of these studies also show that generalists may perform best or lay more eggs when offered a mixed diet (Bilde and Toft, 1994; Evans et al., 1999). Further, different prey may meet different nutritional needs. Aphidophagous coccinellids have been shown to be highly dependent on aphids as an essential food source for development of larvae (Hodek and Honek, 1996) and for oviposition (Evans, 2000; Richards and Evans, 1998), even though other types of food often supplement their diet (e.g., Hagen, 1987; Hodek and Honek, 1996).

To determine the potential for generalist predators to suppress pests in agroecosystems, the response of the predators to the different pest species must be understood. In a pecan orchard in southern Arizona, only two herbivorous insects are abundant and reach pest status: the blackmargined pecan aphid Monellia caryella (Fitch) and the black pecan aphid Melanocallis caryaefoliae (Davis) (both Sternorrhyncha: Aphididae: Drepanosiphinae: Phyllaphidini). In commercial pecan orchards, both aphids are considered serious pests due to host plant carbohydrate loss, reduction of photosynthesis, and defoliation and yield-losses that may be associated with outbreaks (Tedders, 1978; Wood et al., 1985, 1987).

Both aphid species feed on the compound leaves and co-occur throughout most seasons (Tedders, 1978), although their population peaks are often independent (Petersen, unpublished). In southern Arizona, their most abundant natural enemies are generalist predators, the green lacewings Chrysoperla comanche (Banks) and Chrysopa nigricornis Burmeister (Both Neuroptera: Chrysopidae) (Petersen, unpublished). C. comanche and $C$. nigricornis are both arboreal and occur on several trees and shrubs in the southwestern United States. The latter species is reported to be widely distributed within the Nearctic region (Bickley and MacLeod, 1956). In pecan orchards, oviposition by both species starts in early spring and continues until late autumn, giving rise to several generations per year. Eggs of $C$. comanche are laid singly whereas $C$. nigricornis lays eggs in batches of 10-70 eggs. Perceptions by growers and pest control professionals that the predators are effective only in suppressing $M$. caryella led us to investigate the interactions of these predators with the two aphid species.

Although the two aphid species co-occur in the pecan canopy, differences in physiology, morphology, and behavior could make them differentially attractive or of different food qualities for predators. First, M. caryella excretes copious amounts of honeydew, ten times higher in glucose equivalents than that produced by M. caryaefoliae (Wood et al., 1987). It has therefore been suggested that the honeydew produced by $M$. caryella may make this species more attractive than M. caryaefoliae to natural enemies (Bumroongsook and Harris, 1992; Harris and Li, 1996). Lacewings have been shown to be attracted to honeydew breakdown products (Hagen, 1986). Second, M. caryaefoliae is olive green to black, appears to be more sclerotized, and bears a number of tubercles on the thorax and abdomen, while $M$. caryella is pale yellow and relatively smooth-bodied (Tedders, 1978). Both aphids are disturbed easily (Tedders and Thompson, 1981), but our casual observations suggest their responses to disturbance to be different; $M$. caryaefoliae individuals are more likely to jump and $M$. caryella to walk or fly. Both reactions are often seen as an escape behavior among aphids (e.g., Brown, 1974; Dixon, 1958; Hajek and Dahlsten, 1987) and may be more or less effective for evading predator attack.

In a previous study, we examined lacewing larval feeding in field cages with one or both aphid species and found no evidence to suggest that larvae fed preferentially on either species (Petersen and Hunter, 2001). Here, we examined whether the two lacewing species distinguish between the two aphid species during oviposition as well as whether the aphids were different in food quality for lacewing performance. Performance was measured as survival, developmental time, cocoon weight at the time of pupation, as well as pre-oviposition time, and the number of eggs laid during the first five days of oviposition.

\section{Materials and methods}

\subsection{Insect cultures}

Monellia caryella and M. caryaefoliae were reared on pecan seedlings germinated from nuts collected in an orchard with 'Wichita' variety pecans intercropped with 'Western Schley' variety as pollinator trees. Stock cultures of C. comanche and C. nigricornis were reared on a mixture of the bird cherry oat aphid Rhopalosiphum padi L. and the green bug Schizaphis graminum Rondani on barley seedlings. All cultures were provided light for 
$15 \mathrm{~h} / \mathrm{d}$. Pecan aphid and lacewing cultures were started from specimens collected in Sahuarita, Arizona, $\left(31^{\circ} 57^{\prime} \mathrm{N}, 111^{\circ} 00^{\prime} \mathrm{W}\right)$ and renewed frequently to prevent adaptation to laboratory conditions.

\subsection{Ovipositional preference}

Chrysopa nigricornis and C. comanche adult females were tested for possible ovipositional preferences among the two pecan aphid species. Because C. nigricornis females require insect prey to develop eggs, females of this species were fed three different aphid diets to test whether food experience during the pre-ovipositional period would influence their ovipositional behavior. Newly eclosed adults were paired (one female and one male), isolated in paper cans $(9 \mathrm{~cm}$ diameter and $6 \mathrm{~cm}$ high) with a mesh screen in the lid, and provided with (1) M. caryella, (2) M. caryaefoliae, or (3) a mixture of $R$. padi and $S$. graminum. All containers were provided with a water vial and a drop of artificial diet consisting of a hydrolyzate of yeast and milk powder (Good Bug Power Meal, Arbico, Tucson, AZ, USA), diluted in water and honey in a ratio of $4: 1: 1$. All females were kept at $22 \pm 1.0^{\circ} \mathrm{C}$.

Experimental females were released in experimental cages $\sim 16 \mathrm{~h}$ after their first oviposition. The $1 \mathrm{~m}^{3}$ cage contained three pecan seedlings, each bearing 6-8 leaves, placed in an equilateral triangle with position randomly assigned. The three pecan seedlings were: (1) an uninfested plant 'control,' (2) infested with $M$. caryella, and (3) infested with $M$. caryaefoliae. Plants used in the latter two treatments were infested with eight adult aphids approximately $18 \mathrm{~d}$ before the start of the experiment. At the time lacewings were introduced, plants infested with M. caryella had on average $267 \pm 21$ aphids $( \pm \mathrm{SE})$ and the median honeydew coverage was 3 (range $0-4$ ). The honeydew coverage was evaluated on a scale from 0 to 4 ; 0 : no honeydew, $1:<25 \%$ of the leaves covered with honeydew, 2: $25-50 \%$ of the leaves covered, 3: 50-100\% covered with honeydew, and $4: 100 \%$ of the leaves cov- ered with a heavy layer of honeydew. Plants infested with M. caryaefoliae had a mean number of $356 \pm 21$ aphids $( \pm \mathrm{SE})$ and a median honeydew coverage of 1 (range $0-2$ ). The number of $M$. caryaefoliae per plant was significantly higher than that of $M$. caryella $\left(F_{1,59}=8.72 ; P<0.01\right)$. One female lacewing was released on the center of the cage floor. Treatments were blocked in time. All experimental cages were kept at $22 \pm 1.0^{\circ} \mathrm{C}$.

The number of eggs laid by $C$. comanche and the number of egg batches laid by $C$. nigricornis were counted on each plant after 24,48 , and $72 \mathrm{~h}$; interim counts were used to discern and correct for egg cannibalism by $C$. nigricornis females. The experiment was terminated after $72 \mathrm{~h}$. Nine C. nigricornis were tested for each food type provided during the pre-oviposition period (27 females total) and 15 C. comanche females were tested in total. In each experiment, a contingency analysis of the total numbers of eggs or egg batches laid on each of the three plant types was performed. Where this test showed a significant difference, a 'Tukey-type multiple comparison' (Zar, 1996) was performed. For C. nigricornis, the effect of pre-oviposition feeding on ovipositional preference was tested by a contingency table with food type, prior to the experiment and plant aphid treatment in the experiment as categories.

\subsection{Suitability of pecan aphids for juvenile development}

The food quality of the two aphids was investigated by providing neonate larvae $(<6 \mathrm{~h}$ old) with aphids ad libitum: (1) M. caryella, (2) M. caryaefoliae, or (3) a mixture of the two aphid species. The larvae were placed individually in petri dishes $(9 \mathrm{~cm}$ diameter) lined with filter paper. Each day, pieces of aphid-infested pecan leaves were introduced and the developmental instar was recorded. When pupation had taken place (appearance of a black dot at one end of the cocoon), the weight of the cocoon was measured on a CAHN 31 electro-balance (Ventron, Cerritos, CA, USA). At eclosion, the sex was

Table 1

Developmental time (days) for juvenile instars and weight of cocoon (mg) after pupation of C. comanche and C. nigricornis when fed ad lib with either M. caryella, $M$. caryaefoliae or a mixture of $M$. caryella and $M$. caryaefoliae at $27 \pm 0.5^{\circ} \mathrm{C}$

\begin{tabular}{|c|c|c|c|c|c|c|c|c|c|c|}
\hline \multirow[t]{2}{*}{ Stage or parameter } & \multicolumn{5}{|c|}{ Chrysoperla comanche } & \multicolumn{5}{|c|}{ Chrysopa nigricornis } \\
\hline & $\begin{array}{l}\text { Females } \\
(n=41)\end{array}$ & $\begin{array}{l}\text { Males } \\
(n=40)\end{array}$ & $F$ & df & $P$ & $\begin{array}{l}\text { Females } \\
(n=52)\end{array}$ & $\begin{array}{l}\text { Males } \\
(n=58)\end{array}$ & $F$ & $\mathrm{df}$ & $P$ \\
\hline Second instar larva (d) & $1.9 \pm 0.1$ & $1.7 \pm 0.1$ & 3.50 & 1,80 & 0.07 & $1.8 \pm 0.1$ & $1.8 \pm 0.1$ & 0.39 & 1,106 & 0.53 \\
\hline Third instar larva (d) & $3.1 \pm 0.1$ & $3.0 \pm 0.1$ & 2.84 & 1,80 & 0.10 & $2.7 \pm 0.1$ & $2.5 \pm 0.1$ & 5.90 & 1,107 & $<0.05$ \\
\hline Number of days in cocoon & $8.6 \pm 0.1$ & $8.4 \pm 0.1$ & 1.22 & 1,80 & 0.27 & $10.2 \pm 0.1$ & $9.8 \pm 0.1$ & 13.30 & 1,108 & $<0.001$ \\
\hline $\begin{array}{l}\text { Weight of cocoon after } \\
\text { pupation }(\mathrm{mg})\end{array}$ & $9.5 \pm 0.2$ & $7.7 \pm 0.1$ & 73.75 & 1,80 & $<0.001$ & $18.2 \pm 0.6$ & $16.2 \pm 0.4$ & 8.87 & 1,109 & $<0.01$ \\
\hline
\end{tabular}

There were no significant differences between aphid treatments within each lacewing species; thus, the pooled data from all treatments are presented here. 
determined. Pairs (one female and one male) that originated from the same food treatment were isolated in paper cartons and provided a water vial and a drop of artificial diet as described above. C. nigricornis were all supplied with a mixture of $R$. padi and $S$. graminum (C. comanche do not require prey as adults). Adult lacewings were checked daily to count eggs and supply with water and food. Females were allowed to oviposit for a period of $5 \mathrm{~d}$. Developmental time for eggs was determined by keeping eggs separately in gel capsules to prevent cannibalism. Petri dishes with juveniles and paper cartons with adults were all kept in a climate-controlled chamber at $27^{\circ} \mathrm{C} \pm 0.5,65 \% \mathrm{RH}$, and 15:9 (L:D) h. Treatments were blocked in time (See Table 1 for number of replicates). For each lacewing species, developmental time and weight at pupation were analyzed by analysis of variance using lacewing sex and aphid species as main factors. The interaction term was not significant and thus not presented. Data for the preoviposition period were analyzed by analysis of variance using aphid species as main factor. Data for females of each species were further analyzed with a $t$ test for comparison of the different treatments. For each species, a contingency analysis of the survival of neonate larva to adult eclosion per treatment was performed.

\section{Results}

\subsection{Ovipositional preference}

Both chrysopid species showed a significant preference for ovipositing on pecan seedlings infested with aphids (Fig. 1). However, only C. comanche showed a significant preference for one of the aphid species, laying more eggs on pecan seedlings with $M$. caryaefoliae than on those with $M$. caryella, even though leaves on pecan seedlings infested with $M$. caryella had more honeydew than plants infested with $M$. caryaefoliae. The relative abundance of aphids may have contributed to this preference, because plants with $M$. caryaefoliae bore a significantly greater number of aphids than plants with $M$. caryella (see Section 2). C. nigricornis females exhibited no ovipositional preference between the aphid species nor were they more likely to oviposit on plants bearing one of the two species of aphids because of experience; pre-oviposition feeding treatment did not significantly influence the oviposition site $\left(\chi^{2}=4.54 ; \mathrm{df}=4 ; P=0.34\right)$.

\subsection{Suitability of aphid species for larval development}

Monellia caryella and $M$. caryaefoliae appeared equally suitable for development of $C$. comanche and C. nigricornis. Developmental time (eggs to eclosion) was approximately $20 \mathrm{~d}$ for both lacewings on both aphid species with a significantly faster development for males

\section{C. comanche}

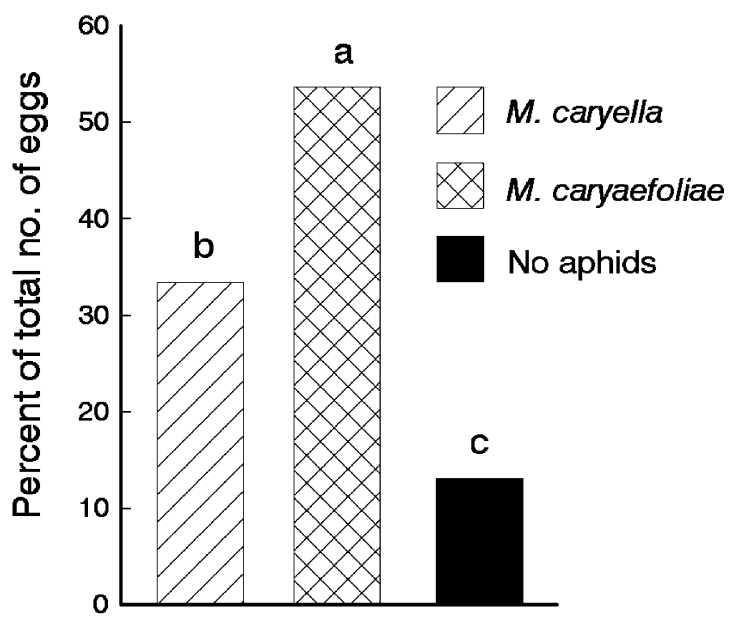

C. nigricornis

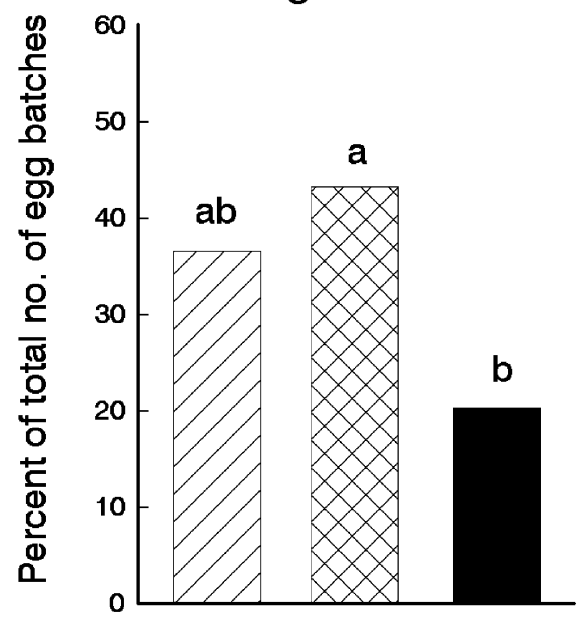

Fig. 1. Percentage of the total number of eggs (C. comanche) or of the total number of egg batches ( $C$. nigricornis) laid on pecan seedlings in an ovipositional preference experiment. The total number of eggs laid by $C$. comanche was 69 and the total number of egg batches laid by $C$. nigricornis was 74 . Bars that are marked with different letters are significantly different $(P<0.05)$ according to a 'Tukey-type multiple comparison.'

(Table 1). Developmental time of female $C$. nigricornis from neonate larva to eclosion was significantly longer (1 d) for individuals fed the mixed aphid diet compared to specimens fed only M. caryaefoliae (Fig. 2). No difference in developmental time was found for $C$. comanche females. Female cocoons were significantly heavier than male; $C$. comanche females were $23 \%$ larger than males and $C$. nigricornis females were 13\% larger (Table 1). C. nigricornis females had a significantly greater cocoon weight when larvae were fed M. caryaefoliae (Fig. 2). C. comanche females did not show this difference. The developmental time of eggs laid by experimental females was $4.0 \pm 0.02 \mathrm{~d}$ for $C$. comanche $(n=61)$ and $3.2 \pm 0.06$ $\mathrm{d}$ for $C$. nigricornis $(n=46)$ and mortality of eggs was $7.6 \%$ for C. comanche and $20.7 \%$ for C. nigricornis. 

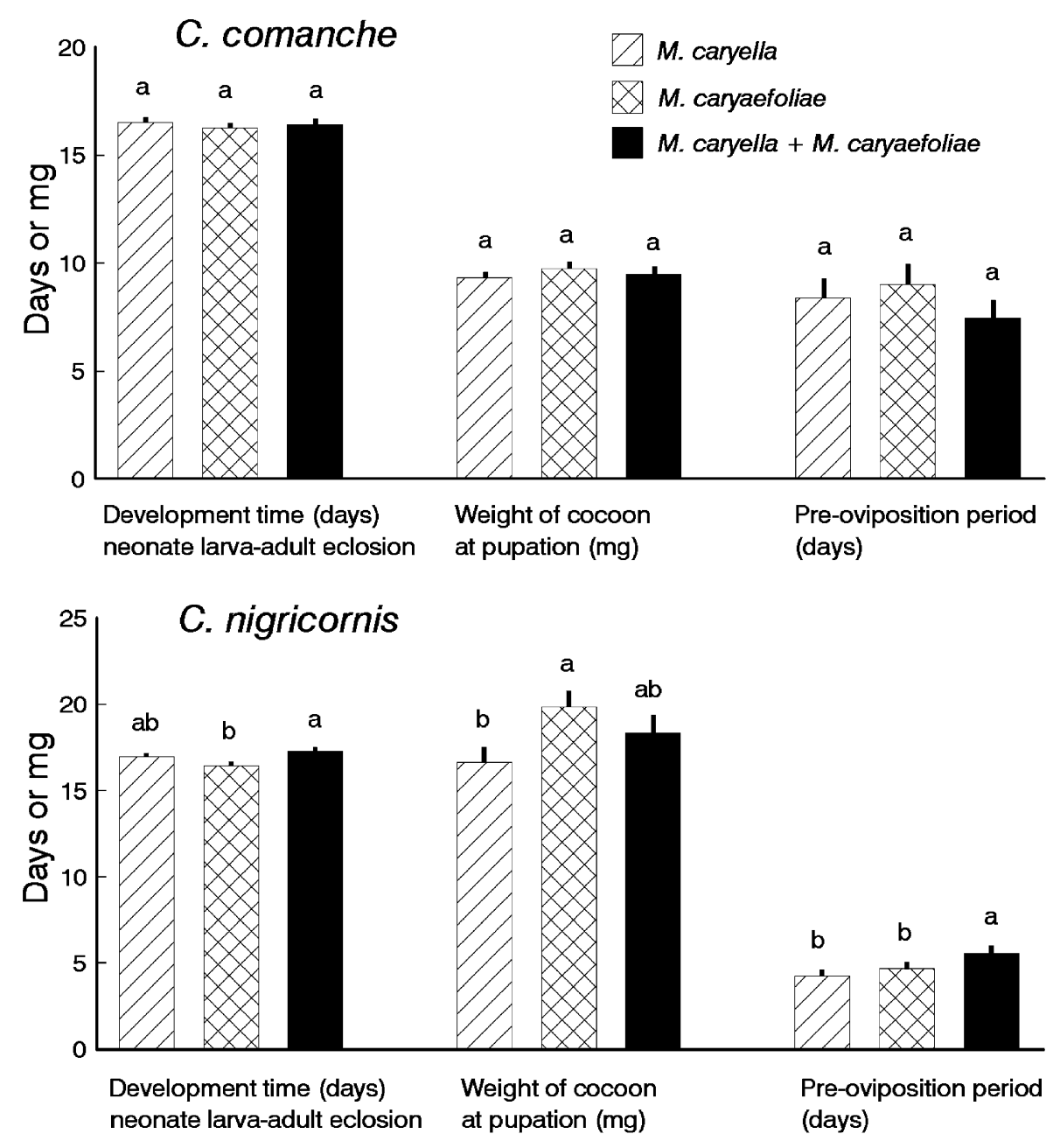

Fig. 2. Developmental time from neonate larva to adult eclosion (days), weight of cocoon right after pupation (mg), and pre-oviposition period (days) for C. comanche and C. nigricornis females. During larval development, all specimens were fed pecan aphids ad libitum. Bars within each parameter marked with different letters are significantly different $(P<0.05)$, according to a $t$ test.

Mortality during juvenile development was low for both species and was not influenced by aphid treatment (C. comanche: $\chi^{2}=0.38 ; \mathrm{df}=2 ; P=0.83$, C. nigricornis: $\chi^{2}=0.33 ; \mathrm{df}=2 ; P=0.85$ ). From neonate larva until adult eclosion, C. comanche experienced $8 \%$ mortality and C. nigricornis $4 \%$. Six percent of C. nigricornis failed to eclose properly and died within $48 \mathrm{~h}$, even though they were provided water and aphid prey. No adults of $C$. comanche failed to eclose.

The mean pre-oviposition time (after eclosion) was $8.2 \pm 0.5 \mathrm{~d}$ for $C$. comanche when fed the artificial diet only and $4.7 \pm 0.2 \mathrm{~d}$ for $C$. nigricornis when fed the artificial diet and cereal aphids. For C. nigricornis, the preoviposition time was significantly affected by aphid treatment provided to the larvae; specimens that were fed a mixture of $M$. caryaefoliae and $M$. caryella experienced a longer pre-oviposition period than specimens fed only one of the aphid species during larval development (Fig. 2). C. comanche did not show any significant differences in their pre-oviposition period with respect to aphid treatment (Fig. 2).
During the first five days of oviposition, $C$. comanche laid $85.0 \pm 4.1$ eggs $( \pm \mathrm{SE})$ and $C$. nigricornis laid $112.9 \pm 10.2$ eggs $( \pm \mathrm{SE})$ on average. The number of eggs laid per female during this period was highly variable in both species, but could not be explained by the type of aphids that the larvae were fed $\left(C\right.$. comanche: $F_{2,28}=$ $0.26 ; P=0.77, C$. nigricornis: $F_{2,43}=1.52 ; P=0.23$ ). Cocoon weight was significant in its influence on the total number of eggs laid during the first five days of oviposition for both $C$. comanche $(P=0.0034)$ (Fig. 3) and C. nigricornis $(P=0.01)$ (Fig. 4).

\section{Discussion}

\subsection{Ovipositional preference}

Our results on female ovipositional preference indicate that these green lacewings are more likely to lay eggs on foliage with aphids and honeydew than on clean plants. An earlier study by Hagen (1986) found that 


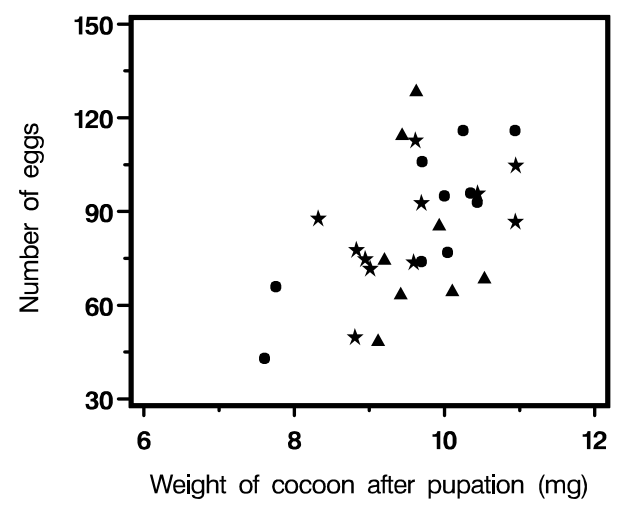

Fig. 3. Total number of eggs per $C$. comanche female during the first five days of oviposition as a function of weight of the cocoon after pupation. The symbols refer to the species of pecan aphids that the females were fed during juvenile development. (\) M. caryaefoliae, $(\bullet)$ M. caryella, and $(\star)$ a mixture of $M$. caryaefoliae and $M$. caryella. Regression: $y=-43.23+13.31 x$, where $x$ is the weight of the cocoon right after pupation, $n=29, r^{2}=0.27 ; P=0.0034$.

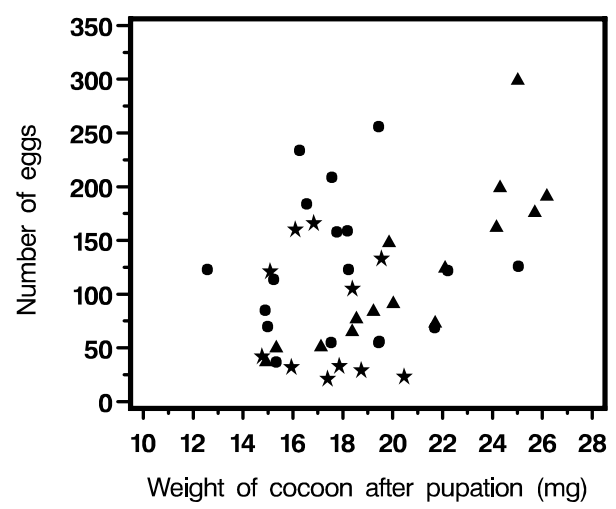

Fig. 4. Total number of eggs per C. nigricornis female during the first five days of oviposition as a function of weight of the cocoon after pupation. Symbols as in Fig. 3. Regression: $y=-33.49+7.80 x$, where $x$ is the weight of the cocoon right after pupation, $n=44$, $r^{2}=0.15 ; P=0.01$.

another green lacewing species $C$. carnea (Stephens) uses a breakdown product of honeydew as a kairomone when a volatile synomone from the plant is also present. Harris and Li (1996) suggest that M. caryella may be more important in attracting natural enemies to pecans because this species excretes ten times more honeydew in glucose equivalents than $M$. caryaefoliae (Tedders and Wood, 1987). This might be most important for the localization of prey and its host plant at longer distances than investigated here. Lacewings are likely often navigating tens or hundreds of meters in orchards that are typically several hectares in area and with trees 3$15 \mathrm{~m}$ in height. However, at the short distances of this experiment (cage of $1 \mathrm{~m}^{3}$ ), C. comanche females showed a significant preference for plants with the more abundant $M$. caryefoliae. C. nigricornis females did not distinguish between the two pecan aphids nor between the amount or type of honeydew produced by the aphids. These data suggest that at a smaller spatial scale, for example, when females are choosing among leaves on a branch, the presence of honeydew may be important as may the species or relative abundance of aphids, but the amount or quality of honeydew is likely to be less important.

\subsection{Larval and early adult performance}

Both aphids tested were suitable for juvenile development of $C$. comanche and C. nigricornis. Aphid diet did not influence developmental time or mortality, which was very low, nor was fecundity of offspring affected directly. All of these data suggest that the two aphid species are both good quality foods. The higher cocoon weight of $C$. nigricornis when larvae were fed $M$. caryaefoliae suggests that this prey may be a marginally better food source for this species. It would be interesting to determine whether larval development in the field, where species abundance varies both during the growing season and between years, shows a similar effect of aphid food source on life history parameters.

Estimates obtained for the life history parameters of the lacewings are within the range observed by other workers (Tauber and Tauber, 1972, 1983; Zheng et al., 1993). It is difficult to interpret the biological significance of the significantly longer pre-oviposition period when $C$. nigricornis are fed a mixed aphid diet as larvae in view of the non-significant differences for other life history parameters.

Differences in the two lacewings' life history might lead one to predict that the effect of larval feeding on fecundity might be different. Both $C$. comanche and $C$. nigricornis species feed on honeydew and nectar as adults (Hagen et al., 1970; Principi and Canard, 1984), but $C$. nigricornis must also feed on prey as an adult (Tauber and Tauber, 1974). Zheng et al. (1993) suggest that only nutrients available from juvenile feeding are available for adult reproduction in the chrysopid C. carnea (Stephens), a congener of $C$. comanche. In general, insects that feed while reproducing show a weak correlation between body size and fecundity and a positive correlation between consumption and fecundity (e.g., Mills, 1981; Slansky, 1980). We therefore predicted that only the fecundity of $C$. comanche would be correlated with body size. However, our results obtained from the first five days of oviposition show a significant relationship between body size and the number of eggs laid for both chrysopid species, although the statistical significance was greatest for $C$. comanche. One might expect a larger difference between the two species to emerge if one measured the lifetime fecundity. We would predict an even stronger influence of body size on fecundity in C. comanche, but less of an influence of body size in C. nigricornis due to adult female predation. 


\subsection{Preference-performance of generalist predators}

Although herbivores have been the focus of most studies on the link between ovipositional preference and offspring performance, evidence suggests that predators' ovipositional behavior is similarly refined with respect to a number of variables (Bargen et al., 1998; Doumbia et al., 1998; Kan, 1988; Lucas and Brodeur, 1999; Sadeghi and Gilbert, 2000). However, the fitness values of these choices require a more rigorous evaluation for more species. We found that only one of the lacewing species tested showed an ovipositional preference with respect to the aphid species studied and that both lacewings performed equally well on both prey. Given the equivalent performance, the lack of preference by $C$. nigricornis appears to be adaptive yet this is perhaps a less convincing demonstration of selection shaping ovipositional behavior than if some discrimination had been made and reflected performance differences. The ovipositional preference by $C$. comanche was not correlated with a better performance of juveniles.

In this study, we evaluated the performance when different aphid species were provided as prey. However, it would also be interesting to determine whether risk of egg predation or parasitism varies in the field with respect to whether eggs are laid on clean leaves, on leaves with only honeydew or on leaves infested with one or the other aphid species. Chrysopids are attacked by a diverse suite of egg and larval-pupal parasitoids (Clancy, 1946), many of which we have reared from field-collected individuals (Petersen, unpublished). Further, cannibalism by conspecifics and intraguild predation by heterospecific lacewings and other predators are likely to be at least periodically important in this system, as it is in some others (Rosenheim et al., 1993, 1995, 1999), and may contribute to mortality of lacewings. Honeydew has been shown to be a contact kairomone for aphid hyperparasitoids (Budenberg, 1990; Grasswitz, 1998). If it is similarly attractive to lacewing egg and larval parasitoids and other aphid predators that facultatively attack lacewings, one might predict that the risk of lacewing natural enemies being attracted to oviposition sites would be the highest for leaves bearing high densities of $M$. caryella and the lowest for clean leaves. On the other hand, Lucas and Brodeur (1999) suggest that neonate larvae of the aphidophagous cecidomyiid Aphidoletes aphidimyza Rondani might have reduced predation risk on leaves with higher aphid densities because of a dilution effect. It remains to be tested whether generalist predator ovipositional behavior reflects an adaptive balance between providing offspring with suitable prey and reducing risk of natural enemy attack.

Generalist predators may be especially valuable in the agroecosystem because of their ability to sustain their populations on a variety of prey. The generalized ovipositional habits and consumption of aphid prey that we observed are ideal for suppression of a pest complex such as $M$. caryella and $M$. caryaefoliae in pecans. $C$. comanche and $C$. nigricornis are the most abundant predators in pecan orchards in southern Arizona, occurring throughout the growing season. Under field conditions, food limitation is likely to be common because periods of high aphid densities are usually rather short (Petersen, unpublished). That the predators may easily switch from one to another means that lacewing populations that build up when one aphid population increases are then present to prevent the other species from erupting. In this way, the two aphid species serve as alternate food sources for the lacewings.

\section{Acknowledgments}

We thank John Oswald and Catherine Tauber for help with initial identification of the green lacewing species, Farmers Investment Company (FICO) for access to an unsprayed orchard block, and to Mike Kilby for his introduction to the pecan system in Arizona. Ann Hajek, Jonas Sandström, and an anonymous reviewer provided us with constructive criticism of earlier versions of this manuscript. This work was partly funded by USDA-ARS funds for Southwestern Irrigated Pecan Research and MKP was funded by a 2-year post-doctoral fellowship by the Danish Research Councils.

\section{References}

Albuquerque, G.S., Tauber, M.J., Tauber, C.A., 1997. Life-history adaptations and reproductive costs associated with specialization in predacious insects. J. Anim. Ecol. 66, 307-317.

Bargen, H., Saudhof, K., Poehling, H.-M., 1998. Prey finding by larvae and adult females of Episyrphus balteatus. Entomol. Exp. Appl. 87, 245-254.

Bickley, W.E., MacLeod, E.G., 1956. A synopsis of the Nearctic Chrysopidae with a key to the genera. Proc. Entomol. Soc. Wash. 58, 177-202.

Bilde, T., Toft, S., 1994. Prey preference and egg production of the carabid beetle Agonum dorsale. Entomol. Exp. Appl. 73, 151156.

Brodeur, J., Geervliet, J.B.F., Vet, L.E.M., 1998. Effects of Pieris host species on life history parameters in a solitary specialist and gregarious generalist parasitiod (Cotesia species). Entomol. Exp. Appl. 86, 145-152.

Brown, H.D., 1974. Defensive bahaviour of the wheat aphid, Schizaphis graminum (Rondani) (Hemiptera: Aphididae) against Coccinellidae. J. Entomol. 48, 157-165.

Budenberg, W.J., 1990. Honeydew as a contact kairomone for aphid parasitoids. Entomol. Exp. Appl. 55, 139-148.

Bumroongsook, S., Harris, M.K., 1992. Distribution, conditioning, interspecific effects of blackmargined aphids and yellow pecan aphids (Homoptera: Aphididae) on pecan. J. Econ. Entomol. 85, 187-191. 
Clancy, D.W., 1946. The insect parasites of the Chrysopidae (Neuroptera). Univ. Calif., Berkeley, Publ. Entomol. 7 (13), 403496.

Dixon, A.F.G., 1958. The escape responses shown by certain aphids to the presence of the coccinellid Adalia decempunctata (L.). Trans. R. Entomol. Soc. Lond. 110, 319-334.

Doumbia, M., Hemptinne, J.-L., Dixon, A.F.G., 1998. Assessment of patch quality by ladybirds: role of larval tracks. Oecologia 113, 197-202.

Evans, E.W., 2000. Egg production in response to combined alternative foods by the predator Coccinella transversalis. Entomol. Exp. Appl. 94, 141-147.

Evans, E.W., Stevenson, A.T., Richards, D.R., 1999. Essential versus alternative foods of insect predators: benefits of a mixed diet Oecologia 121, 107-112.

Grasswitz, T.R., 1998. Contact kariomones mediating the foraging behavior of the aphid hyperparasitoid Alloxysta victrix (Westwood) (Hymenoptera: Charipidae). J. Insect Behav. 11, 539548.

Hagen, K.S., 1986. Ecosystem analysis: plant cultivars (HPR), entomophagous species and food supplements. In: Boethel, D.J., Eikenbarry, R.D. (Eds.), Interactions of Plant Resistance and Parasitoids and Predators of Insects. Ellis Horwood, New York, pp. 151-197.

Hagen, K.S., 1987. Nutritional ecology of terrestrial insect predators. In: Slansky, F., Rodriguez, J.G. (Eds.), Nutritional Ecology of Insects, Mites, Spiders, Related Invertebrates. Wiley, New York, pp. 533-577.

Hagen, K.S., Mills, N.J., Gordh, G., McMurtry, J.A., 1999. Terrestrial arthropod predators of insect and mite pests. In: Bellows, T.S., Fisher, T.W. (Eds.), Handbook of Biological Control. Principles and Applications of Biological Control. Academic Press, San Diego, pp. 383-503.

Hagen, K.S., Tassan, R.L., Sawall, E.J., 1970. Some ecophysiological relationships between certain Chrysopa, honeydews and yeasts. Boll. R. Lab. Entomol. Agraria Portici 28, 113-134.

Hajek, A.E., Dahlsten, D.L., 1987. Behavioral interactions between three birch aphid species and Adalia bipunctata larvae. Entomol Exp. Appl. 45, 81-87.

Harris, M.K., Li, T., 1996. The blackmargined aphid as a keystone species: a predator attractor redressing natural enemy imbalances in pecan systems. In: Mattson, W.J., Niemela, P., Rousi, M. (Eds.), Dynamics of Forest Herbivory: Quest for Pattern and Principle, pp. 112-117, USDA For. Serv. Gen. Tech. Rep. NC-183, N.C. For. Exp. Sta., St. Paul, MN 55108.

Hodek, I., Honek, A., 1996. Ecology of Coccinellidae. Kluwer Academic Publishers, Dordrecht, 464 pp.

Janssen, A., 1989. Optimal host selection by Drosophila parasitoids in the field. Funct. Ecol. 3, 469-479.

Kan, E., 1988. Assessment of aphid colonies by hoverflies. II. Pea aphids and 3 syrphid species: Betasyrphus serarius (Wiedemann), Metasyrphus frequens Matsumura and Syrphus vitripennis (Meigen) (Diptera: Syrphidae). J. Ethol. 6, 135-142.

Kraaijeveld, A.R., Nowee, B., Najem, R.W., 1995. Adaptive variation in host-selection behaviour of Asorbara tabida, a parasitoid of Drosophila larvae. Funct. Ecol. 9, 113-118.

Lucas, E., Brodeur, J., 1999. Oviposition site selection by the predatory midge Aphidoletes aphidimyza (Diptera: Cecidomyiidae). Environ. Entomol. 28, 622-627.

Mills, N.J., 1981. Some aspects of the rate of increase of a coccinellid. Ecol. Entomol. 6, 293-299.

Nylin, S., Janz, N., 1993. Oviposition preference and larval performance in (Lepidoptera: Nymphalidae): the choice between bad and worse. Ecol. Entomol. 18, 394-398.

Petersen, M.K., Hunter, M.S., 2001. Variation in the outcome of competition between two aphid species on pecan: plants matter more than predators. Oikos 92, 107-118.
Principi, M.M., Canard, M., 1984. Feeding habits. In: Canard, M., Semeria, Y., New, T.R. (Eds.), Biology of Chrysopidae. Dr W. Junk Publisher, The Hague, pp. 76-91.

Richards, D.R., Evans, E.W., 1998. Reproductive responses of aphidophagous lady beetles (Coleoptera: Coccinellidae) to nonaphid diets: an example from Alfalfa. Ann. Entomol. Soc. Am. 91, 632-640.

Rosenheim, J.A., Kaya, H.K., Ehler, L.E., Marois, J.J., Jaffee, B.A., 1995. Intraguild predation among biological-control agents: theory and evidence. Biol. Control 5, 303-335.

Rosenheim, J.A., Limburg, D.D., Colfer, R.G., 1999. Impact of generalist predators on a biological control agent, Chrysoperla carnea: direct observations. Ecol. Appl. 9, 409-417.

Rosenheim, J.A., Wilhoit, L.R., Armer, C.A., 1993. Influence of intraguild predation among generalist insect predators on the suppression of an herbivore population. Oecologia 96, 439449 .

Sadeghi, H., Gilbert, F., 2000. Oviposition preferences of aphidophagous hoverflies. Ecol. Entomol. 25, 91-100.

Scott, S.M., Barlow, C.A., 1990. Effect of hunger on the allocation of time among pea plants by the larvae of an aphidophagous hover fly, Eupeodes corollae [Dipt: Syrphidae]. Entomophaga 35, 163172.

Slansky, F., 1980. Effect of food limitation on food consumption and reproductive allocation by adult milkweed bugs, Oncopeltus fasciatus. J. Insect Physiol. 26, 79-84.

Tauber, M.J., Tauber, C.A., 1972. Larval diapause in Chrysopa nigricornis: sensitive stages, critical photoperiod, termination (Neuroptera: Chrysopidae). Entomol. Exp. Appl. 15, 105111

Tauber, M.J., Tauber, C.A., 1974. Dietary influence on reproduction in both sexes of five predacious species (Neuroptera). Can. Entomol. 106, 921-925.

Tauber, M.J., Tauber, C.A., 1983. Life history traits of Chrysopa carnea and Chrysopa rufilabris (Neuroptera: Chrysopidae): influence of humidity. Ann. Entomol. Soc. Am. 76, 282-285.

Tedders, W.L., 1978. Important biological and morphological characteristics of the foliar-feeding aphids of pecan. United States Department of Agriculture (USDA). Technical Bulletin Number 1579 , pp. $1-29$.

Tedders, W.L., Thompson, J.M., 1981. Histological investigation of stylet penetration and feeding damage to pecan foliage by three aphids (Hemiptera (Homoptera): Aphididae). In: Johhnson, D. (Ed.), Tree Fruit and Nut Pest Management in the South Eastern United States. Miscellaneous Publication, Entomological Society of America, pp. 69-83.

Tedders, W.L., Wood, B.W., 1987. Field studies of three species of aphids on pecan: an improved cage for collecting honeydew and glucose-equivalents contained in honeydew. J. Entomol. Sci. 22, 23-28.

Thompson, J.N., 1988. Evolutionary ecology of the relationship between oviposition preference and performance of offspring in phytophagous insects. Entomol. Exp. Appl. 47, 3-14.

Toft, S., 1995. Value of the aphid Rhopalosiphum padi as food for cereal spiders. J. Appl. Ecol. 32, 552-560.

Toft, S., Wise, D.H., 1999. Growth, development, survival of a generalist predator fed single- and mixed-species diets of different quality. Oecologia 119, 191-197.

Via, S., 1986. Genetic covariance between oviposition preference and larval performance in an insect herbivore. Evolution 40, 778785 .

Wood, B.W., Tedders, W.L., Dutcher, J.D., 1987. Energy drain by three pecan aphid species (Homoptera: Aphididae) and their influence on in-shell pecan production. Environ. Entomol. 16, $1045-1056$

Wood, B.W., Tedders, W.L., Thompson, J.M., 1985. Feeding influence of three pecan aphid species on carbon exchange and phloem 
integrity of seedling pecan foliage. J. Am. Soc. Hort. Sci. 110, 393397.

Yamaga, Y., Ohgushi, T., 1999. Preference-performance linkage in a herbivorous lady beetle: consequences of variability of natural enemies. Oecologia 119, 183-190.
Zar, J.H., 1996. Biostatistical Analysis, third ed. Prentice-Hall, Upper Saddle River, NJ.

Zheng, Y., Daane, K.M., Hagen, K.S., Mittler, T.E., 1993. Influence of larval food consumption on the fecundity of the lacewing Chrysoperla carnea. Entomol. Exp. Appl. 67, 9-14. 